\title{
Sex Education for Children and Adolescents with Type 1 Diabetes in Camagüey Province, Cuba
}

\author{
Kesia Granela MD, Yohannis Cardoso MD, Antonio Gutiérrez MD, Matilde Carvajal MD
}

\begin{abstract}
Education at the community level is indispensable for control of chronic non-communicable diseases and comprehensive patient care, with diabetes mellitus a case in point. The need is even more pronounced for type 1 diabetes, affecting children and adolescents. Families of diabetic adolescents naturally worry about vulnerability to sexually transmitted diseases, which create risks for glycemic control and the adolescent's health. We felt compelled to explore the issue of sexuality in diabetes education for adolescents, because education can do more than help maintain metabolic control; it can contribute to keeping diabetic children and adolescents on a healthy developmental curve, when combined with the other pillars of diabetes management. Accordingly, we carried out an educational intervention to increase type 1 diabetic adolescents' knowledge of sexuality and sexually transmitted infections. Participants were 20 adolescents in Camagüey Province's central clinic for type 1 diabetes patients. A six-session educational program was developed and implemented. Responses to a questionnaire before and after the program revealed that prior to the intervention only 3 of 20 participants (15\%) demonstrated satisfactory knowledge of the material covered $(\geq 70 \%)$, increasing to $20(100 \%)$ after completion of the program.
\end{abstract}

KEYWORDS Sex education, adolescents, diabetes mellitus, sexually transmitted infections, Cuba

\section{INTRODUCTION}

The physical changes accompanying arrival of puberty and the beginning of adolescence can be disconcerting for these young people and the adults close to them. Adolescents are required to make a series of adjustments to function interpersonally and within their environment, adjustments modulated by the social and cultural milieu in which they develop. The vulnerability of adolescence is especially evident in the sphere of sexuality.[1-4]

Faced with issues of sexuality-including types of sexual activities or behaviors, recognizing love, avoiding unwanted pregnancies and defining sexual roles-adolescents may be exposed to substantial risks and dilemmas. Add to this that they often have insufficient information about sexuality, which can lead to using it as a mode of rebellion, unaware of the risks of pregnancy, sexual transmitted infections (STI) and other problems.[1-5] Thus, these youth need guidance and support for informed decision-making; and sex education that provides them with a better understanding of sexuality and facilitates adoption of health promoting behaviors.[3,4] All this applies to diabetic adolescents, complicated by their disease.

Diabetes mellitus (DM) is a chronic non-communicable disease that constitutes an important health problem because of its high disease burden, risk of comorbidities and mortality, and ensuing social and economic costs.[6] Type $1 \mathrm{DM}$ onset is acute in children and adolescents and evolves rapidly; in this phase the often difficult treatment goal is to maintain the best possible metabolic control to enable normal growth and development, assisting patients to adopt a new lifestyle (behavioral change) that helps them take responsibility for their own DM management.[6] A combination of diet, medication, exercise and education can offer the prompt, active and effective approach needed to prevent or postpone complications, both acute and chronic, and improve prognosis and patient quality of life.[7-9]

Education is a mainstay of comprehensive DM management,[4] particularly among adolescents, as the disease can interfere with the profound physical and psychological changes during this period, affecting social relations and leading to psychosocial problems. The literature reports decreases in amputations and length of hospital stays, as well as marked improvement in glycemic control, among patients who have participated in educational programs.[10] This can be accomplished either one-on-one or in groups, and involve children or adolescents, their parents and broader social circles.

The educational process should begin at disease onset, reinforced in every medical appointment and hospital visit; $[10,11]$ it should be adapted to DM's natural course, providing basic information at onset that is expanded systematically over the lifespan. Like any other therapeutic tool, it should be organized and integrated into overall disease management. The team treating diabetics should receive appropriate training in educational methods and negotiate reasonable and attainable objectives with their patients. Periodic evaluation of these programs is essential.[11-13]

For diabetic adolescents, the focus should be on developments specific to this age group, including sexuality, as this is when responsibility for management progressively shifts to patients themselves. Thus, in addition to general DM education, risk of chronic complications from STIs should be addressed in educational programs. STIs present an even greater risk for diabetic adolescents than for their nondiabetic peers, because of the added problem of altered metabolic control.[14-16]

In 1995, 4\% of reported STI cases (including HIVIAIDS) in Latin America occurred in adolescents.[17] Compared to the period 1980-2000, the first decade of this century has witnessed increases in reports of the number of people living with HIV/ AIDS globally and in Cuba,[18,19] as well as in STIs generally. [18] In Cuba, the National Program for Prevention and Control of Sexually Transmitted Diseases and HIVIAIDS was established in 1986 with the main goal of preventing the infection-disease process from becoming a major population health problem. [19-22]

In light of the responsibility that diabetic adolescents have for progressively managing their disease and the real possibility of complications from illnesses typical of this age, such as STIs, our team undertook a sex education intervention with diabetic adolescents treated at the community-based Pediatric Specialty Polyclinic (PEPC, the Spanish acronym) in the city of Camagüey, capital of the province of the same name. 


\section{INTERVENTION}

Objective Raise awareness about specific aspects of sex education and STIs among type 1 diabetic adolescents treated at the pediatric DM clinic of PEPC's endocrinology service.

Justification In caring for diabetic adolescents, the authors have observed gaps in their knowledge of particular dangers presented by STIs. Diabetic adolescents' increased risk from STls makes guidance an essential part of their medical management.[14-16] Addressing the knowledge gap is therefore a major objective of our preventive efforts.

Participants A random sample of 20 adolescents (aged 12-19 years ) with type $1 \mathrm{DM}$ of the 57 receiving treatment in PEPC's pediatric DM clinic in 2012. The sample size was chosen because such interventions are more successful with small groups. [14] The adolescents were in junior high (grades 7-9) and high school (grades 10-12). They and their guardians provided written informed consent to participate in the educational program and its evaluation; the study was approved by the research ethics committee of the Eduardo Agramonte Piña Pediatric Clinical-Surgical Teaching Hospital.

Activities Like other intervention efforts, the program followed three well-defined steps: diagnosis, the intervention itself and evaluation.

Diagnosis A survey was applied (see Appendix) designed by the authors to identify participants' sociodemographic characteristics and knowledge of sexuality and STIs. Questions covered age, sex, sexual experience, age at initiation of sexual relations, sources of information on sex, birth control and knowledge of STIs. The latter included concept (Q4 in Appendix), main STIs (Q5), risk behaviors (Q6), transmission routes (Q7), clinical signs (Q8), prevention (Q9, Q10), STI effects on DM (Q11), and what to do in the event of an STI (Q12). Each of the nine questions was assigned 10 points; the number of correct answers varied among questions, so the percentage for each was calculated and converted to the nearest whole point out of ten. The maximum number of possible points for the questionnaire was 90; overall knowledge was considered satisfactory if there were $\geq 70 \%$ correct responses ( $\geq 63$ of 90 points).

Intervention The authors offered a course in the PEPC pediatric diabetes clinic over a six-week period ending in May 2012. There were six weekly one-hour sessions that included a workshop using productive teaching methodology and participatory techniques such as brainstorming.[23] The model also included a DM day camp (a week of day-long educational and recreational activities for young diabetics and their parents or guardians) in the Camagüey Diabetic Care Center.

Evaluation Three months after the intervention, the same questionnaire was again administered to measure knowledge acquisition. SPPS version 10.0 and Word Office XP were used to process data and compare pre- and post-intervention knowledge.

\section{RESULTS}

The 20 adolescents in the study included 12 women and 8 men; 7 women $(58.3 \%)$ had initiated sexual relations -2 $(16.7 \%)$ when they were aged $<12$ years_and 3 men (37.5\%) (Table 1$)$.
Table 1: Diabetic adolescents' age at initiation of sexual relations $(n=20)$

\begin{tabular}{|l|r|r|r|r|}
\hline \multirow{2}{*}{ Age } & \multicolumn{2}{|c|}{ Women } & \multicolumn{3}{c|}{ Men } \\
\cline { 2 - 6 } & No. & \multicolumn{1}{|c|}{$\%$} & No. & \multicolumn{1}{c|}{$\%$} \\
\hline$<12$ years & 2 & 16.7 & 0 & 0.0 \\
\hline $12-16$ years & 4 & 33.3 & 2 & 25.0 \\
\hline $17-19$ years & 1 & 8.3 & 1 & 12.5 \\
\hline Total with SR & 7 & 58.3 & 3 & 37.5 \\
\hline Total without SR & 5 & 41.7 & 5 & 62.5 \\
\hline Total & 12 & 100.0 & 8 & 100.0 \\
\hline
\end{tabular}

SR: sexual relations

Sources of information on sexuality in descending order of frequency were: school (65\%), friends (50\%), television (45\%), family $(40 \%)$, medical team $(30 \%)$ and radio $(15 \%)$.

Before the intervention, only five adolescents (25\%) demonstrated understanding of the concept of STIs (Q4), compared with $16(80 \%)$ afterwards. Prior to the educational intervention, only two items elicited $>70 \%$ correct responses. $16(80 \%)$ were able to correctly identify STIs (Q5) from a list of diseases and $20(100 \%)$ were able to identify which methods of birth control prevent STIs. Percentages of correct responses for other questions ranged from $25 \%$ to $65 \%$. In contrast, following the intervention, at least $70 \%$ of adolescents gave correct responses to all questions, and $100 \%$ were able to correctly identify STIs (Table 2).

Table 2: Knowledge of STIs in diabetic adolescents pre- and post intervention $(n=20)$

\begin{tabular}{l|r|r|}
\multirow{2}{*}{ Item } & $\begin{array}{r}\text { Adolescents with correct responses } \\
\text { No. (\%) }\end{array}$ \\
\cline { 2 - 3 } & \multicolumn{1}{|c|}{$\begin{array}{r}\text { Pre } \\
\text { Concept of STI (Q4) }\end{array}$} & $16(80.0)$ \\
\hline Main STIs (Q5) & $16(80.0)$ & $20(100.0)$ \\
\hline Risk behaviors (Q6) & $13(65.0)$ & $17(85.0)$ \\
\hline STI transmission routes (Q7) & $12(60.0)$ & $14(70.0)$ \\
\hline Clinical signs (Q8) & $12(60.0)$ & $15(75.0)$ \\
\hline STI prevention (Q9) & $20(100.0)$ & $20(100.0)$ \\
\hline Birth control (Q10) & $5(25.0)$ & $18(90.0)$ \\
\hline STI effects on DM (Q11) & $9(45.0)$ & $16(80.0)$ \\
\hline What to do if infected with STI & $10(50.0)$ & $15(75.0)$ \\
(Q12) & $3(15)$ & $20(100.0)$ \\
\hline$\geq 70 \%$ of questionnaire content &
\end{tabular}

STI: sexually transmitted infection

Before the intervention, only 9 (45\%) knew that STIs can cause acute DM complications (Q11), even though such effects can potentially be lethal. The number increased to $16(80 \%)$ after the intervention (Table 2). Prior to the intervention only $3(15 \%)$ adolescents scored $\geq 70 \%$ on the questionnaire; all participants scored $\geq 70 \%$ afterwards.

\section{LESSONS LEARNED}

There was substantial improvement, measurable at three months, in adolescents' knowledge of sexual topics such as risk behaviors and how to prevent STIs, and even more important, how STIs can affect and complicate DM. The fact that before the intervention fewer than half were aware of their particular vulnerability to STIs underlines the need for systematic education in this patient group. The intervention-a course with participatory techniques 
for small groups of diabetic adolescents-proved useful in educating these patients about their health and provided them greater knowledge, favoring adoption of healthy behaviors. We recom- mend establishing systematic sex education interventions as part of DM education for type 1 diabetic adolescents, including those recently diagnosed. -1 .

\section{APPENDIX}

\section{Sex Education for Diabetic Adolescents: Pre- and Postintervention Questionnaire}

Q1. Sex:

$$
\text { 1.1__ Male 1.2__Female }
$$

\section{Q2. Grade}

\section{Q3. General information}

3.1 Do you know about sexually transmitted infections (STI) and HIV-AIDS?

Yes_ No

3.2 Where do you get your information about them? $\begin{array}{lll}\text { radio } & \text { TV } \\ \text { family } & \text { friends } & \text { school } \\ \text { (a) } & \text { medical team }\end{array}$

3.3 (a) Have you had sexual relations? Yes_ No_ _ (age) (b) Did you use birth control? Yes _ No

3.4 Have you ever had an STI? Yes__ No Which?

Q4. Mark True or False:

4.1__STIs are transmitted only through sexual contact.

4.2 STIs have other transmission routes.

4.3_ STIs are those that are transmitted through sex games.

Q5. Which of the following are STIs? (Mark True or False):

\begin{tabular}{|c|c|}
\hline 5.1_Hepatitis B & 5.8_Herpes simplex type \\
\hline 5.2_Common cold & 5.9 Chickenpox \\
\hline 5.3 Syphilis & 5.10 Genital warts \\
\hline 5.4_Gonorrhea & 5.11_Intestinal parasites \\
\hline Leptospirosis & 5.12 Trichomonas \\
\hline HIVIAIDS & 5.13 Leprosy \\
\hline 5.7 Chlamydia & \\
\hline
\end{tabular}

Q6. Mark an $X$ beside all the following statements that are True:

6.1__ Having multiple partners puts one at risk for contracting STIs.

6.2__Anal sex prevents STI infections.

6.3_Reducing the number of sexual partners reduces risk of contracting STIs.

6.4_Monogamy ensures safer sex.

6.5 _ Casual sexual encounters increase the risk of contracting STIs.

6.6_Everyone who has unprotected sexual relations is at risk of contracting STIs.

Q7. Mark an X beside the ways STIs can be contracted:

7.1__Contact with your partner's personal objects

7.2_ Penetration of the penis in the vagina

7.3_Anal coitus

7.4_Kisses, sweat, saliva or tears from infected individuals

7.5_ Pregnancy (mother to fetus before or during birth)

7.6__Blood transfusions

7.7 _ Insect bites

Q8. Mark True or False:

8.1_ Secretion is an important clinical manifestation of gonorrhea in men.
8.2__ Syphilis begins with a genital sore.

8.3 _ A baby can be born with an STI.

8.4 _ Some STIs are asymptomatic in women.

8.5 _ Syphilis affects only the genital organs.

8.6_HIVIAIDS is almost always associated with skin sores.

8.7 A wart in the genital area makes us suspect an STI.

8.8_Warning signs of STIs include secretions from the penis or vagina, sores, and warts or peeling skin around the anus, vagina or mouth.

Q9. Mark an $X$ beside all the following that are ways to prevent STIs:

9.1_Sexual relations without exchange of saliva, secretions or genital contact

9.2__ Oral birth control

9.3_Condoms

9.4_Diaphragm

9.5_Abstention from sexual relations

9.6_Rhythm method

Q10. Mark an $X$ beside all the following statements that are True:

10.1 Birth control methods provide safer sex.

10.2_Birth control methods are those that are used to prevent pregnancies.

10.3_Selecting a couple's birth control method is a decision made by a single partner.

10.4_ The ideal birth control method should be inexpensive, easy to use and free of side effects.

10.5 IUDs always cause infections and bleeding in women

10.6_Condoms protect against STIs and help prevent pregnancy.

Q11. Mark True or False:

11.1_STIs do not affect control of type 1 diabetes mellitus.

11.2_ STIs cause acute complications such as hyperglycemia.

11.3_ _ STIs do not aggravate the chronic complications of diabetes mellitus.

Q12. If you contracted a sexually transmitted infection, what would you do first? (Mark with an X):

12.1_Begin antibiotic treatment

12.2_Consult your partner

12.3 _Use birth control

12.4_Consult your medical team

12.5_Abstain from sexual relations

12.6 Consult your parents

12.7 _ Consult your best friend

\section{Scoring quide}

Item Correct response

$4 \quad 4.2$

$5 \quad 5.1, .3, .4, .6, .7, .10, .12$

$6 \quad 6.1, .3, .4, .5, .6$

$7 \quad 7.2, .3, .5, .6$

$8 \quad 8.1, .2, .3, .4, .6, .8$

$9 \quad 9.1, .3, .4, .5$

$10 \quad 10.1, .2, .4, .6$

$11 \quad 11.2$

$12 \quad 12.4$ 


\section{REFERENCES}

1. de Velazco M. Salud y sexología en la adolescencia. Sexol Soc. 2003;2(4):20-2. Spanish.

2. Pick S, Givaudan M, Saldivar A. La importancia de los factores psicosociales en la educación sexual en los adolescentes. Perinatol Reprod Hum. 1996;10(2):143-50. Spanish.

3. Waster W, Johnson J, Koldni RC. La sexualidad humana: La sexualidad y la adolescencia. Havana: Editorial Científico-Técnica; 1998. p. 229-75. Spanish

4. Basulto-Marrero E, Machado-del Risco E, Medina-Alí FE. Intervención educativa sobre las ETS NIH/SIDA en adolescentes con Diabetes Mellitus Tipo 1 en la ciudad de Camagüey. Ciencias Holguín [Internet]. 2012 Jan-Mar [cited 2012 Mar 21];18(1)1-11. Available from: http://redalyc .uaemex.mx/redalyc/pdf/1815/181522730013 .pdf. Spanish.

5. Ciego A. Conocimiento sobre sexualidad en embarazadas adolescentes. Trabajo de terminación de la especialidad de MGI [thesis]. [Camagüey (CU)]: Policlínico Tula Aguilera; 2000. p. 1-8. Spanish.

6. Craig ME, Hattersley A, Donaghue KC. Definition, epidemiology and classification of diabetes in children and adolescents. ISPAD Clinical Practice Consensus Guidelines 2009 Compendium. Pediatric Diabetes. 2009 Sep;10(Suppl 12):3-12.

7. Couper JJ, Donaghue KC. Phases of diabetes in children and adolescents. ISPAD Clinical Practice Consensus Guidelines 2009 Compendium. Pediatric Diabetes. 2009 Sep;10(Suppl 12):13-6.

8. Donaghue KC, Chiarelli F, Trotta D, Allgrove J, Dahl-Jorgensen K. Microvascular and macrovascular complications associated with diabetes in children and adolescents. ISPAD Clinical Practice Consensus Guidelines 2009 Compendium. Pediatric Diabetes. 2009 Sep;10(Suppl. 12):195-203.

9. Bangstad HJ, Danne T, Deeb LC, Jarosz-Chobot P, Urakami T, Hanas R. Insulin treatment in children and adolescents with diabetes. ISPAD Clinical Practice Consensus Guidelines 2009 Compendium. Pediatric Diabetes. 2009;10(Suppl 12):82-99.

10. Swift PGF. Diabetes education in children and adolescents. ISPAD Clinical Practice Consensus
Guidelines 2009 Compendium Pediatric Diabetes. 2009;10(Suppl 12):51-7.

11. Markowitz SM, Carper MM, Gonzalez JS Delahanty LM, Safren SA. Cognitive- behavioral therapy for the treatment of depression and adherence in patients with Type 1 diabetes: pilot data and feasibility. Prim Care Companion CNS Disord. 2012;14(2).

12. Hood KK, Rohan JM, Peterson CM, Drotar D Interventions with adherence-promoting components in pediatric Type 1 diabetes: meta-ana lysis of their impact on glycemic control. Diabetes Care. 2010 Jul;33(7):1658-64.

13. Robling M, McNamara R, Bennert K, Buttler CC Channon S, Cohen D, et al. The effect of the Talking Diabetes consulting skills intervention on glycaemic control and quality of life in children with Type 1 diabetes: cluster randomised controlled trial (DEPICTED study). BMJ. $2012 \mathrm{Apr}$ 26;344: e2359.

14. García R, Suárez R. La educación a personas con diabetes mellitus en la atención primaria de salud. Rev Cubana Endocrinol. 2007;18(1):2. Spanish.

15. Pérez $A$, Barrios $Y$, Monier $A$, Berenguer $M$, Martínez I. Repercusión social de la educación diabetológica en personas con diabetes mellitus. MEDISAN. 2009 Jul-Aug;13(4). Spanish.

16. Navarro D. Diabetes Mellitus y sexualidad: experiencias y especulaciones. Sexol Soc 2008:14(37):16-21. Spanish.

17. Gutiérrez D. Intervención educativa sobre infecciones de transmisión sexual en adolescentes en el municipio Camagüey, República de Cuba. Acad Biomédica Digital [Internet]. 2007 Jul-Sep [cited 2012 Mar 5];(32):1-3. Available from: http://vitae.ucv.ve/pdfs/VITAE_1006.pdf. Spanish.

18. World Health Organization [Internet] Geneva: World Health Organization; c2013. Global Health Observatory HIVIAIDS; 2013 [cited 2013 Jun 6] [about 1 screen]. Available from: http://www.who .int/gho/hiv/en/

19. Miranda O, Fariñas AT, Coutín G, Nápoles M, Lara $\mathrm{H}$, Bueno LE. Panorámica de la infección por el VIH en Cuba, 1986-2007. Rev Cubana Hig Epidemiol. 2009 May-Aug;47(2):1-7. Spanish.
20. Miranda O, Fariñas AT, Coutín G, Nápoles M, Lara H, Lago T. Comportamiento de la epidemia de VIH en Cuba. Rev Med Electrón. 2012 JanFeb;34(1):7-24. Spanish.

21. Ramos I, Louro I, Fariñas AT, Llanusa S, Rojo N. Participación multisectorial en la respuesta nacional para la prevención y atención a la epidemia del VIH/SIDA, República de Cuba, 20072008. Med Social. 2010 Sep;5(3):192-202. Spanish.

22. González I, Hoyos A, Martínez LC, González I, Lama A. Intervención educativa sobre ETS-VHI/ sida en estudiantes de la enseñanza preuniversitaria. IPVC Carlos Marx. Años 2008-2009. Universidad de Ciencias Médicas Dr. Juan Guiteras Gener. Matanzas. Rev Méd Electrón. 2010 JulAug;32(4). Spanish.

23. Equipo de Educación Popular. Centro Memorial Dr. Martin Luther King, Jr. Técnicas de Participación. Havana: Editorial Caminos; 1999. p. 20, 37, 54, 55, 94. Spanish.

\section{THE AUTHORS}

Kesia Granela Cortiñas (Corresponding author: kgc@hpc.cmw.sld.cu), family physician and pediatric endocrinologist. Instructor, Eduardo Agramonte Piña Clinical-Surgical Pediatric Teaching Hospital (HPDCQ-EAP), Camagüey Province, Cuba.

Yohannis Cardoso Benavides, pediatrician, HPDCQ-EAP, Camagüey Province, Cuba.

Antonio Gutiérrez Macías, pediatric endocrinologist. Assistant professor, HPDCQ-EAP, Camagüey Province, Cuba.

Matilde Carvajal, pediatrician and consulting professor, HPDCQ-EAP, Camagüey Province, Cuba.

Submitted: September 12, 2012

Approved for publication: May 30, 2013

Disclosures: None 